\title{
Effect of predisposing factors on microbial loads in camel milk along the pastoral dairy value chain in Kenya
}

\author{
Samuel Muyoma Nato ${ }^{1,4^{*}}$, Joseph Wafula Matofari', Bockline Omedo Bebe ${ }^{2}$ and Christian Huelsebusch ${ }^{3}$
}

\begin{abstract}
The aim of this study was to map the camel milk value chain and establish the predisposing factors for increase in microbial counts in milk along the chain. Isiolo County was chosen for the study. Data collection was done through key informant interviews, structured interview schedules, observation and microbial analysis of milk samples. During milk sampling, milk temperature, environmental temperature, time and volume of milk from which the sample was taken were recorded. Along the value chain, microbial counts in milk increased significantly from $\log _{10} 4.91 \pm 1.04$ CFU/ $\mathrm{ml}$ at production to $\log _{10} 7.52 \pm 1.32 \mathrm{CFU} / \mathrm{ml}$ at Nairobi market for total viable counts and $\log _{10} 3.68 \pm 1.28 \mathrm{CFU} / \mathrm{ml}$ at production to $\log _{10} 6.42 \pm 1.13 \mathrm{CFU} / \mathrm{ml}$ at the Nairobi market for coliform counts. At production, milking persons neither washed their hands nor cleaned the camels' udder before milking, and plastic, non-food grade containers were the only form of receptacles used for milk along the chain. The relationship between microbial counts and time taken to transport milk along the chain was significant while the volume of milk in the receptacle had no effect on microbial counts. The milk was held at a temperature of between 28 and $32.5^{\circ} \mathrm{C}$ before delivery to secondary collection centres from $10: 15$ am to $6: 30 \mathrm{pm}$ for cooling. Training on milk quality for milk handlers at the collection centre had no effect on microbial counts. Affordable access to low-cost food grade plastic containers as well as cooling milk in the individual receptacles within two hours of milking, without bulking and refilling again into the receptacles for transportation, as is the practice, would reduce microbial counts. Similarly, training on milk quality should start at production where milk contamination is initiated. Finally, milk value addition would improve milk shelflife enabling access to distant markets. This would greatly improve the livelihoods of the pastoral camel milk producers.
\end{abstract}

Keywords: Camel milk, Isiolo, Microbial load, Predisposing factors

\section{Introduction}

Milk production in Kenya is dominated by cattle and camels which contribute 86 and $10 \%$ of total milk production respectively (GOK 2010). Kenya has a camel population of over 3.3 million (KNBS 2010), and are particularly important in North Eastern region of the country where a large community of Somali and related ethnicities are more familiar with camel milk (FAO 2011). Along the camel milk value chain, only $5 \%$ of the milk is processed while the rest is consumed at household level and hotels in the

\footnotetext{
* Correspondence: muyomanato@gmail.com

'Department of Dairy and Food Science and Technology, Egerton University,

P.O Box 536-20115 Egerton, Nakuru, Kenya

${ }^{4}$ Department of Pure and Applied Sciences, Technical University of

Mombasa, P.O Box 90420-80100, Mombasa, Kenya

Full list of author information is available at the end of the article
}

milk-producing areas and urban centres such as Isiolo, Nairobi and Nakuru (Musinga et al. 2008). The bulk of the milk stays at ambient temperature for a long time before reaching either the cooling centre or the market (GOK 2010). The milk is commonly handled in plastic containers which are not just difficult to clean but also the poor quality of water used to clean them enhances microbial levels in milk (Mwangi et al. 2000). The milk handlers also pool the milk from different sources without carrying out quality tests (Younan and Abdulrahman 2004). These factors result in increased microbial counts along the chain as reported by Matofari et al. (2013) with the presence of pathogenic microorganisms such as Salmonella spp., Staphylococcus aureus and Streptococcus spp. reported (Matofari et al. 2013; Odongo et al. 2016; Kashongwe et 
al. 2017). The main problem, however, faced by the traders along this chain is milk spoilage (Wayua et al. 2012). The occurrence of these factors, and their contribution to increase in microbial counts in milk along the chain have not been reported. Empirical studies of these factors are therefore important in prioritizing interventions to not only reduce milk spoilage along the chain but also reduce health risks to which camel milk consumers may be exposed.

\section{Study area}

This study was carried out between February and August 2015 within Isiolo County and along the value chain to Nairobi (Figure 1), Kenya. Isiolo County lies between longitudes $36^{\circ} 50^{\prime}$ and $39^{\circ} 30^{\prime}$ East and latitudes $0^{\circ} 5^{\prime}$ and $2^{\circ}$ North and has a total area of $25,605 \mathrm{~km}^{2}$ (Noor et al. 2013). Isiolo County is a typical arid and semi-arid region (Noor et al. 2013) with average annual rainfall of $418 \mathrm{~mm}$ (Mati et al. 2005) and a camel population of 39,084 (KNBS 2010); most camel owners practice pastoralism, with camel milk being an important source of livelihoods (Wayua et al. 2012). Most of the marketed milk ends up either in Isiolo town, or Eastleigh market in Nairobi city, a distance of $275 \mathrm{~km}$ to the south of Isiolo town (Noor et al. 2013).

\section{Methods}

Study design and field data collection

A cross-sectional study was set up to collect data from milk handlers. Primary and secondary data was collected to map the camel milk value chain. Primary data was collected by observation and use of structured interview schedules administered to actors along the chain, from producers, collection centre operators, transporters and traders. A total of 90 milk handlers were interviewed face-to-face. The questions were translated into Swahili or the preferred language of the respondent where appropriate. Key informant interviews were held with the secretary of the Camel Owners Association and the chairpersons of the Anolei women's group and Tawakal group to validate the findings. All the participants in this study voluntarily provided data and information.

\section{Milk sample collection and laboratory analysis}

Milk samples were collected from the camel during milking, and along the value chain from primary

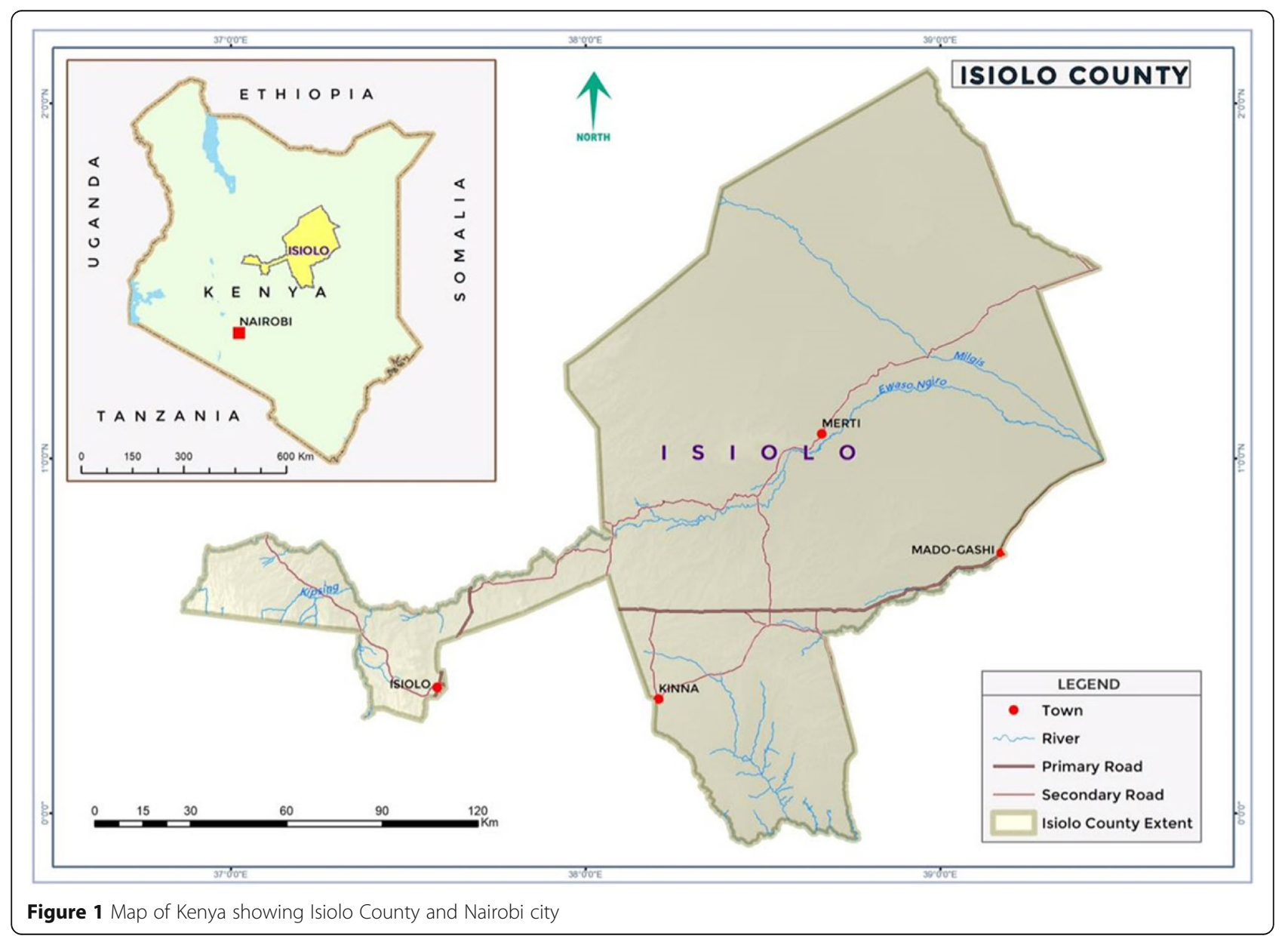


collection sites near the camel herds, secondary collection centres in Isiolo town, transporters, and traders both in Isiolo and Nairobi. In Isiolo, 76 milk samples were collected from the interviewed actors in Isiolo and 55 milk samples collected from Nairobi traders. The size of the containers from which milk was sampled ranged from 3, 5, 10 to $20 \mathrm{l}$. Sampling was done in $60-\mathrm{ml}$ sterile sampling bottles and transported in a cool box at $4{ }^{\circ} \mathrm{C}$ to the laboratory in Isiolo County referral hospital for samples from Isiolo and University of Nairobi's Food microbiology laboratory for samples from Nairobi. The analysis was done within four hours after sample collection. The samples were analysed for total viable counts, coliform counts and enterobacteriaceae counts. During sampling, the time of sample collection was recorded as well as the environmental and milk temperature. All the milk samples were voluntarily provided by the participants.

Determination of total viable counts (TVC) was done as described by Messer et al. (1985) for the standard plate count. A milk sample measuring $1 \mathrm{ml}$ was diluted sixfold (1:10) using buffered peptone water for all the samples except the samples from Nairobi which were diluted tenfold (1:10). One millilitre from each dilution was delivered onto a sterile petri dish. This was done in duplicate. It was then followed by pouring about $20 \mathrm{ml}$ of molten (approx. $45^{\circ} \mathrm{C}$ ) Plate Count Agar (Oxoid) prepared according to the manufacturer's instructions. The inoculum were then gently mixed by alternate clockwise and anticlockwise movement for three minutes and left for $30 \mathrm{~min}$ on the bench to solidify. The plates were then incubated at $32{ }^{\circ} \mathrm{C}$ for $48 \mathrm{~h}$ followed by counting of colonies. Plates with colonies between 30 and 300 from the lowest dilution were counted and reported as colonyforming units per millilitre of milk (CFU/ml). Determination of coliforms and enterobacteriaceae followed the same procedure except that the media used was MacConkey agar (Oxoid) and the temperature of incubation was $37^{\circ} \mathrm{C}$ for $24 \mathrm{~h}$. All the colonies on the plate were counted to represent enterobacteriaceae counts, while pink/red colonies were counted as coliforms (lactose fermenters).

\section{Statistical data analysis}

Data was subjected to statistical analyses using SAS version 9.0 (SAS Institute Inc., Cary, NC, USA). The statistical analyses involved determination of frequencies and arithmetic means, correlation between factors that affect microbial loads, and regression between independent and dependent variables. Shapiro-Wilk test was carried out to determine normality of data when $n<30$. The microbial counts were transformed to $\log _{10}$ and reported as mean \pm standard deviation $\mathrm{CFU} / \mathrm{ml}$ of milk. All the statistical tests were done at a significant level of $p \leq 0.05$. Information from the respondents which was validated by the key informants was used to map the value chain.

\section{Results}

\section{Description of the pastoral camel milk value chain}

The camel milk value chain is summarized in Figure 2.

The major milk producing areas in Isiolo were Burat2, Kulamawe, Shaab, Harakote, Ngaremare, Laglava, Dahayal, Shambani, Mlango, Gotu, Malbi Shilmi, Kobi Fora and Elhat. The main stakeholders involved in the value chain were camel herd owners, cooperative societies, transporters, traders, County veterinary office and non-governmental organizations. The camel herd owners employ herders to look after the camels. For the health of the camels, government extension officers were available from the County offices to provide vaccination and treatment. Non-governmental organizations also offer support in animal health. The herd sizes ranged from about ten camels to hundreds of camels.

The lactating camels were milked twice in the morning, usually at 6:00 am and 8:00 am, and the milk was first bulked at the boma/kraal (fenced enclosure). Milk

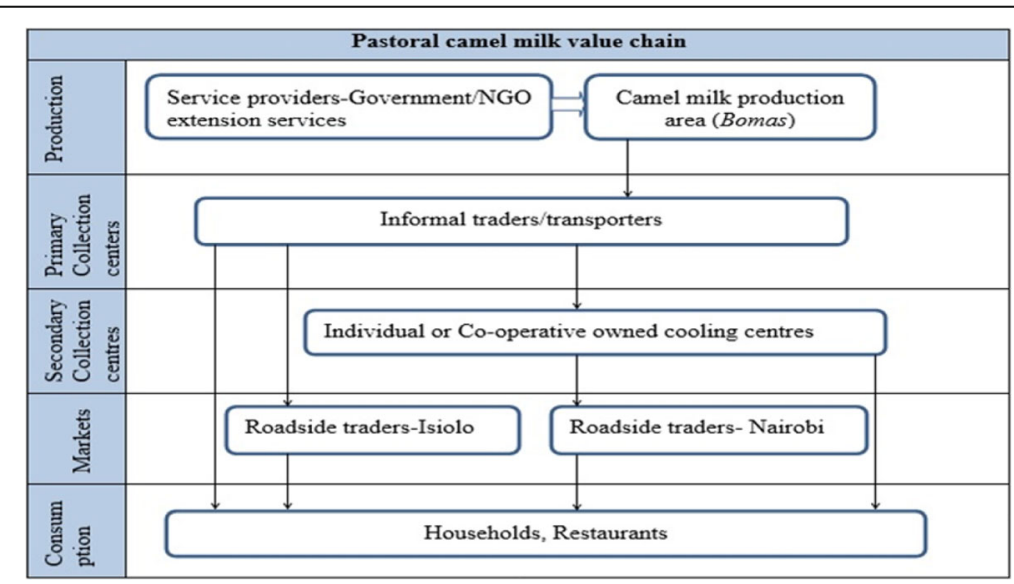

Figure 2 Pastoral dairy value chain for camel milk from Isiolo County 
for the herd owner's home consumption was separated from that to be marketed. The milk to be marketed was then collected by transporters or traders from the primary collection centres which were close to the herd.

Most of the marketed milk was bulked at the groupowned secondary collection centres run by Anolei women's group and Tawakal group. The Anolei women group handled up to 25001 per day while Tawakal handled $500 \mathrm{l}$ per day. On arrival at these collection centres, the milk was tested for alcohol stability and bulked in a chill tank at $4{ }^{\circ} \mathrm{C}$. Milk that failed the test was not bulked but cooled in its container in a separate cooler. The milk would then be sold as suusa, kulel or orawakandi (types of fermented milk, suusa being sweet-sour, orawa-kandi being bitter-sour and kulel tastes between suusa and orawa-kandi). The milk bulked in the chill tank would be emptied again in plastic receptacles the following day at 5:00 am and loaded on buses for transport at ambient temperature to Nairobi, a journey of about seven hours. In Nairobi's Eastleigh estate, milk traders receive the milk for sale to home consumers, hotels and restaurants within Nairobi. Occasionally, some milk is transported to other towns such as Nakuru. Secondary milk collection centres run by individuals handle between 20 and 1001 per day. Other local operators cool the milk and sell it to traders within Isiolo, hotels, restaurants and home consumers.

Different modes of transport were used for milk transportation along the chain. Delivery of milk from production to primary collecton centres, usually a distance of $<1 \mathrm{Km}$, was dominated by transport on foot at $67 \%$, followed by use of donkeys at $22 \%$, and vehicles at $11 \%$. Delivery of milk to the secondary collecton centres was dominated by motorcycles at $42 \%$, with vehicles at $24 \%$. The rest of the milk (34\%) was first delivered by vehicles to the Milk stage within Isiolo town where middlemen bought the milk and delivered it to the secondary collectoin centres using wheelbarrows. Transport of milk to Nairobi city was done only using passenger vehicles with milk kept in plastic containers (Fig. 4) that were used to deliver milk to the collection centre.

\section{Microbial loads of milk along the chain}

Total viable counts (TVC) of milk from individual camels increased significantly from $4.91 \pm 1.04$ at production to $6.49 \pm 0.77$ at secondary collection centres and $7.52 \pm 1.32$ at the Nairobi market. Coliform count (CC) at production was $3.68 \pm 1.28$ which also increased significantly to $6.42 \pm 1.13$ at Nairobi market. Similarly, enterobacteriaceae counts also increased significantly from $3.89 \pm 0.98$ at production to $5.29 \pm 1.10$ at secondary collection centre, and $6.49 \pm 1.13$ at the Nairobi market. Milk bulked at the camel boma had TVC of $5.09 \pm 0.60$ and CC of $3.44 \pm 1.52$, both of which increased significantly at the secondary collection centre and Nairobi market.

At the primary collection centre, TVC, CC and enterobacteriaceae were $5.09 \pm 0.60,3.14 \pm 0.93$ and $3.19 \pm 0.77$, respectively. These increased significantly during transport of milk to the secondary collection centre and to Nairobi market. All the counts increased significantly from the secondary collection centre to the Nairobi market. The microbial load along the chain from production to Nairobi market is summarized in Figure 3.

Predisposing factors for increased microbial counts in milk General hygiene (udder hygiene, milking personnel hygiene, milking container type and cleanliness and excessive human handling of milk)

During the study period, there was neither hand washing nor udder cleaning before milking the camels. All the milk containers were made of non-food grade plastic with non-hygienic design (Figure 4).

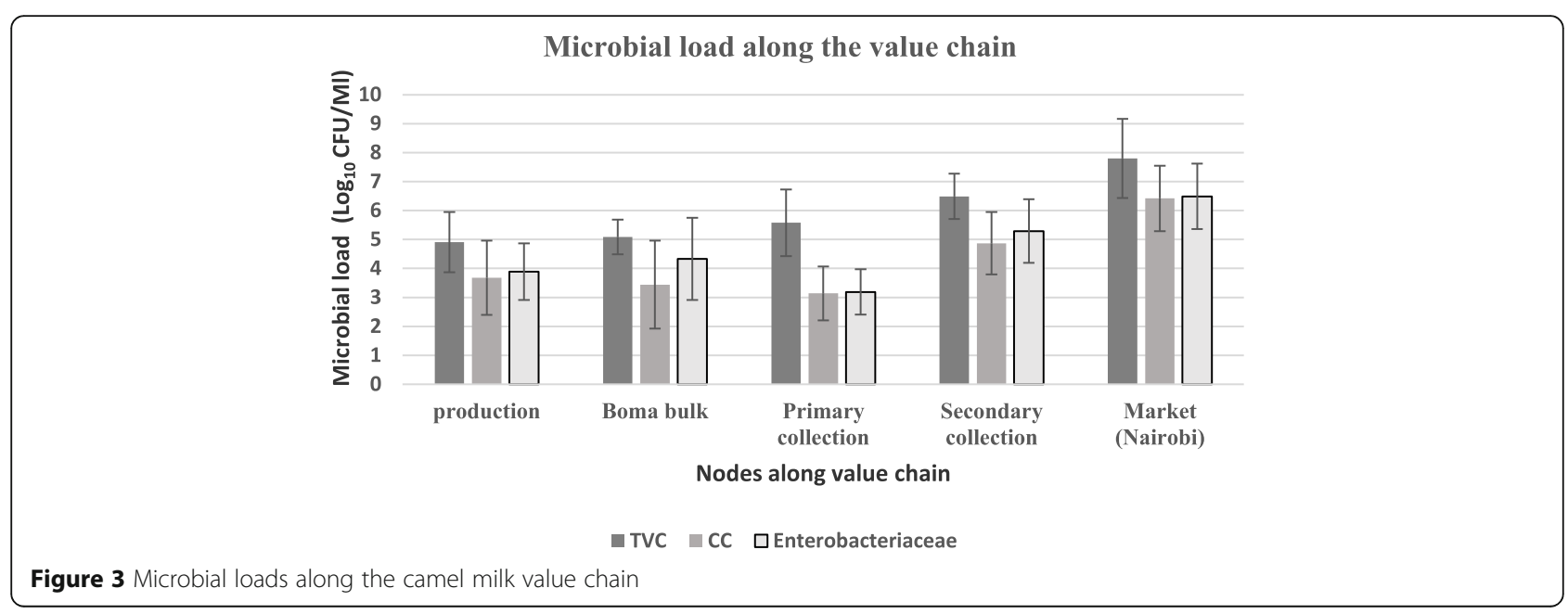




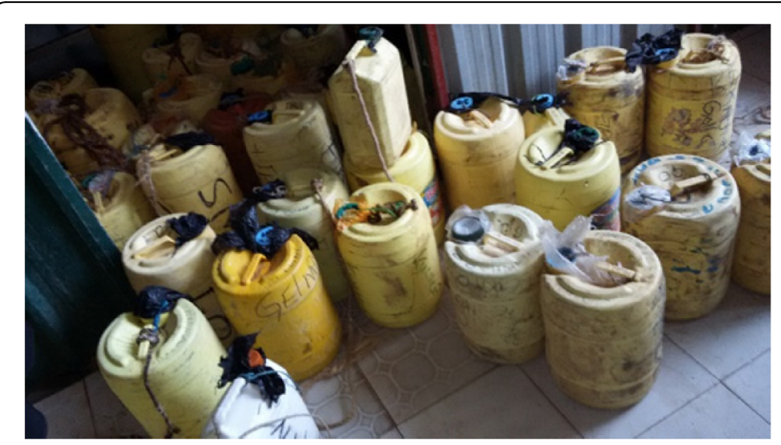

Figure 4 Milk in plastic containers at the reception of a milk collection centre in Isiolo

The containers were previously used for vegetable oil. At the secondary collection centres, group members were involved in all activities from milk reception to record-taking, predisposing the milk to further microbial contamination due to excessive human handling.

The pastoral milk production area had no water supply, apart from water that was brought by milk traders from Isiolo town. This water was hardly enough for cooking or drinking, let alone any form of hygiene. All the milk containers were cleaned in either Isiolo town or Nairobi city using running water and soap. The containers were then smoked for disinfection using wood from especially acacia trees. Although these factors influence microbial loads in milk, they were the same in the study area, and their effect on microbial load in the milk could not be determined from this survey.

Effect of holding time and temperature on microbial counts Milking was done between 6:00 am and 8:30 am and the milk delivered to the primary collection centre where the milk was picked by transporters or traders to the subsequent nodes along the value chain. The mean pick-up time was 10:58 am $\pm 28 \mathrm{~min}$. The average delivery time to the secondary collection centre was 11:47 am $\pm 1 \mathrm{~h}$ 40 min with a range from 10:15 am to $6: 33 \mathrm{pm}$. On the day of sampling, 2001 of milk from Kulamawe which is $80 \mathrm{~km}$ from Isiolo town had not been delivered by 7:00 pm because the vehicle had mechanical problems, which was said to be not unusual. The collected milk is bulked in a chill tank and cooled overnight to $4{ }^{\circ} \mathrm{C}$. At 5:00 am the following morning, the milk was filled into plastic containers and loaded onto buses for transportation to Nairobi where it is delivered at about 11:30 am. However, during the study, $2500 \mathrm{l}$ of milk from one secondary collection centre had not been dispatched to Nairobi because of disagreement on pricing between the owners of milk at the collection centre and the agents in Nairobi. Due to limited capacity of refrigeration, half the volume of milk was not refrigerated but still transported to Nairobi with a delay of $24 \mathrm{~h}$.
Although this is not a common occurrence, it demonstrates the challenges along the value chain that would lead to high microbial count in milk and eventually milk loss through spoilage.

The mean ambient temperature along the chain from production to secondary collection centre was $30.8 \pm 1.04{ }^{\circ} \mathrm{C}$ with a minimum of $28{ }^{\circ} \mathrm{C}$ and a maximum of $32.5{ }^{\circ} \mathrm{C}$ while the milk temperature had a mean of $30.7 \pm 1.4{ }^{\circ} \mathrm{C}$ with a minimum of $28{ }^{\circ} \mathrm{C}$ and a maximum of $35{ }^{\circ} \mathrm{C}$. The milk at the secondary collection centre is then cooled to $4{ }^{\circ} \mathrm{C}$ in a bulk tank. It is then returned to the plastic containers and transported to Nairobi where the milk temperature rises again to $17.8 \pm 2.7{ }^{\circ} \mathrm{C}$. The ambient temperature during milk sampling in Nairobi was $22.5^{\circ} \mathrm{C}$.

There was a strong correlation between ambient and milk temperature (adj. $R^{2}=0.90181, p<0.0001$ ), and therefore, only data on milk temperature was used for modelling in this study. For microbial loads, correlation between TVC and CC was strong with adj. $R^{2}=0.54233$ and $p=0.0004$ while that between TVC and enterobacteriaceae had adj. $R^{2}=0.9028$ and $p<0.0001$. Only data on TVC was therefore used in further statistical analysis.

The correlation between time and milk temperature was equally strong (adj. $R^{2}=0.84158, \quad p<0.0001$ ). However, due to their importance in microbial growth, each was subjected to simple regression analysis with TVC. The relationship between TVC and time was found to be significant (adj. $R^{2}=0.1473, p=0.0045$ ) while that between TVC and temperature was found not to be significant (adj. $R^{2}=0.0527, p=0.073$ ).

\section{Effect of milk volume on microbial counts}

Along the chain, from production to the secondary collection centre, the relationship between TVC and the volume of milk contained in a receptacle was not significant with adj. $R^{2}=0.05$ and $t$ value $=40$. However, larger receptacles had marginally lower microbial counts compared to smaller receptacles.

\section{Effect of level of training of milk handlers on microbial counts}

At the production level, none of the operators had any training on milk quality. These were the same operators who transported milk to the primary collection centre. At the secondary collection centre, $44 \%$ of the operators had training on milk quality. The mean TVC of the milk handled by those who were trained on milk quality was $6.68 \pm 0.74$ while those who had not been trained had a mean of $6.18 \pm 0.71$. The counts were however not statistically different with $p=0.06154$. 


\section{Discussion}

\section{The pastoral camel milk value chain}

The pastoralists often move from one place to another in search of grazing land and water for their animals. Milking of lactating camels occurs at the boma (kraal) where the pastoralists would have pitched camp. The milk would then be taken to the nearest primary collection centre which is usually temporary and only exists till the pastoralists move with the herd to another grazing area. This therefore creates a challenge in milk collection because the traders and transporters sometimes have challenges in tracking the herders. The lack of roads makes it even more difficult for the milk to be collected. Motorbikes therefore are the most effective means of transport from the hinterland to the secondary collection centres. Vehicle transport is used to transport milk from distant milk production areas such as Kulamawe and Gotu. Similarly, only vehicle transport is available to deliver milk to Nairobi. In Nairobi, the milk is received by milk agents who then apportion the milk to the traders. The traders quickly take away the milk for sale at the roadside or to restaurants. The whole value chain is informally controlled by a few people in Isiolo and their associates in Nairobi. Any activities to improve the quality of the milk along the chain will have to involve these actors, who incidentally, benefit at the expense of producers.

\section{Predisposing factors for microbial loads along the chain General hygiene (udder hygiene, milking personnel hygiene, milking container type and cleanliness and excessive human handling of milk)}

Poor udder hygiene has been linked to high microbial counts in milk (Gleeson et al. 2009). The microbial load at production continues to increase in subsequent nodes up to the market as was also reported by Matofari et al. (2013). The non-food grade plastic milking containers as well as failure to clean hands and the camel's udder contribute to milk contamination, and our work (in press) has isolated Escherichia coli from both the udder surface and the hands of the milking persons. The identified challenge was the lack of appropriate milk containers and unavailability of water for maintenance of udder and milking persons' hygiene.

At the Anolei and Tawakal secondary collection centres, group members are involved in most activities from milk reception to record-taking. The collection centre was therefore a beehive of activities, and the inordinate human presence and excessive manual handling increases the risk of milk contamination. To reduce excessive human handling and exposure of milk by pooling it into chill-tanks and transferring the milk back to the plastic receptacles, the alternative is to cool milk in their original containers in a cold store, before transporting it to Nairobi the following day in the morning. Nongovernmental organizations such as the Netherland Development organization (SNV) have supported the groups to acquire aluminium churns for milk handling. Despite this, milk is still transported in unhygienic plastic containers since aluminium churns are a challenge for transport of milk by bus to Nairobi due to milk spillage and weight. The bus operators therefore only accept to transport milk in plastic containers. The use of food grade plastic containers would be an alternative to aluminium churns to overcome this challenge.

\section{Milk holding time and temperature}

Time and temperature are two of the most important extrinsic factors affecting microbial growth, and generally, milk should be cooled to $4{ }^{\circ} \mathrm{C}$ within two hours of milking (Jay et al. 2005). In this study, between production and secondary collection, milk was held at an ambient temperature of between 28 and $32{ }^{\circ} \mathrm{C}$ for up to $12 \mathrm{~h}$. This substantially increases microbial counts of the milk and accounts for significant increase in microbial loads from production to the secondary collection centre. There was indeed a significant relationship between time and TVC between production and the secondary collection centre despite the result having a low adj. $R^{2}$ which can be attributed to transforming microbial counts to $\log _{10}$. Since the secondary collection centres have cooling facilities, microbial growth could be curtailed if milk was delivered less than two hours after milking. Cooling the milk to $4{ }^{\circ} \mathrm{C}$ overnight at the secondary collection centre, then transporting it to Nairobi at ambient temperature, a journey of seven hours, compounds the problem of increased microbial counts. In this study, regressing microbial counts against temperature was not found to have a significant relationship because of a small range in the milk temperature from production to secondary collection centres.

\section{Relationship between volume of milk and microbial counts}

This relationship between microbial load and volume of milk in the receptacle was not found to be significant. Smaller containers have a large surface area to volume ratio and were expected to have a higher microbial count. However, milk in large containers was likely pooled from different sources, which is considered a risk factor for increased microbial load (Younan and Abdulrahman 2004).

\section{Level of training of operators}

Training of milk handlers has always been advocated as a way of improving milk quality (GOK 2010). In this study, results of microbial counts in milk at the secondary collection centre indicated that there was no significant difference in microbial load of milk handled by individuals trained on milk quality vis a vis those 
without training. It was also observed that the milk handling practices of individuals trained on milk quality were not different from those without training. Training of milk handlers along the chain while neglecting milk handlers at production does not result in reduced microbial load. This is because milk contamination begins at production and the microbial load increases exponentially along the chain due to lack of a cold chain, inappropriate milk containers and non-observance of good hygienic practices. Training should enable the milk handlers and actors along the value chain to adhere to a set of Standard Operating Procedures that limit microbial growth. It was also observed that milk containers are labeled by owners, and even after the milk is bulked for cooling, it is returned to the same containers for transport to Nairobi city. These activities create congestion and excessive handling of the milk at the collectoin centre where everybody wants to track their milk (or containers). The actors at the collection centres therefore not only need training on milk quality but also support to strengthen institutional capacites of the collecton centres so that operations are left to elected directors and trained employees. However, as discussed earlier, there are milk traders/middlemen in Isiolo and Nairobi who benefit from the current arangement at the expense of producers, and they should be brought on board for any effective change to be achieved.

\section{Conclusions and recommendations}

The study found that practices at production and along the chain contribute to high microbial counts in milk. The long time that milk is held at ambient temperature while awaiting collection at primary collection centres, or during transport, contributes to increased microbial load in the milk. Most importantly, training of milk handlers should include all actors starting with the herders at production. This should be complemented by policy to support provision of water not only to support camel husbandry but also hygiene during milking. Supporting the producers, transporters and traders to acquire lowcost food grade plastic containers with a capacity of 10 to $15 \mathrm{~L}$ of milk will not only reduce microbial counts but also be convenient during handling and transportation. Most importantly, design of cheaper and more practical cooling facilities based on solar energy or evaporative cooling using charcoal housing would greatly reduce milk spoilage. Processing of the milk would add value by improving its shelf-life and therefore access distant markets. In addition, the Kenya Bureau of Standards, a government agency established under the Kenyan law (Standard Act, CAP 496), and responsible for quality and standards, should intervene and regulate this industry. Similarly, the Kenya Dairy Board (established under the Dairy Act, CAP 336) has a direct mandate over the dairy industry, and it is therefore required to streamline it. This would greatly improve the livelihoods of the pastoral camel milk producers.

\section{Acknowledgements}

We wish to thank our key informants and all the actors along the value chain for the cooperation they accorded us during the study. We also thank Isiolo County Referal Hospital and University of Nairobi for providing us with laboratory facilities.

\section{Funding}

This study was facilitated by the RELOAD project funded by the German Ministry of Education and Research (BMBF) within the framework of GlobE initiative, grant number 031A247A-D. The funding organization however was not involved in the design of the study. Data collection, analysis, interpretation, and writing of the manuscript were wholly the responsibility of the authors.

\section{Authors' contributions}

SMN collected the data and drafted the paper. JWM and BOB designed the experiment. $\mathrm{CH}$ interpreted the results. All authors read and approved the final manuscript.

\section{Authors' information}

SMN is a PhD (Food Science) candidate at the Department of Dairy and Food Science and Technology, Egerton University, P.O Box 536-20115, Egerton, Kenya, and also an Assistant Lecturer at the Department of Pure and Applied Science, Technical University of Mombasa, P.O Box, 9042080100, Mombasa, Kenya. JWM (PhD, Egerton University) is a Professor of Food Safety/Food Biotechnology at the Department of Dairy and Food Science and Technology, Egerton University, P.O Box 536-20115, Egerton, Kenya. BOB (PhD, Wegeningen UR University, Netherlands) is a Professor of Animal Science at the Department of Animal Science, Egerton University, P.O Box 536-20115, Egerton, Kenya Kenya. CH (Dr. Sc. Agr, University of Hohenheim) is a Livestock Scientist and the Managing Director, German Institute of Tropical and Subtropical Agriculture, SteinstraBe, 19, 37213 Witzenhausen, Germany.

Competing interests

The authors declare that they have no competing interests.

\section{Publisher's Note}

Springer Nature remains neutral with regard to jurisdictional claims in published maps and institutional affiliations.

\section{Author details}

${ }^{1}$ Department of Dairy and Food Science and Technology, Egerton University, P.O Box 536-20115 Egerton, Nakuru, Kenya. ²Department of Animal Science, Egerton University, P.O 536-20115 Egerton, Nakuru, Kenya. ${ }^{3}$ German Institute of Tropical and Subtropical Agriculture, StreinstraBe, 19, 37213 Witzenhausen, Germany. ${ }^{4}$ Department of Pure and Applied Sciences, Technical University of Mombasa, P.O Box 90420-80100, Mombasa, Kenya.

Received: 7 November 2017 Accepted: 25 April 2018

Published online: 30 May 2018

\section{References}

FAO. 2011. Global food losses and food waste. Extent, causes and prevention. International Congress "Save Food", Düsseldorf, Germany. http://www.fao. org/docrep/014/mb060e/mb060e00.pdf. Accessed 15 October 2016.

Gleeson, D., B. O'Brien, J. Flynn, E. O'Callaghan, and F. Galli. 2009. Effect of premilking udder preparation on the microbial counts on teats prior to cluster application. Irish Veterinary Journal 62 (7): 461-467.

GOK (Government of Kenya). 2010. Kenya Dairy Master Plan. Nairobi, Kenya: Ministry of Livestock Development. http://kdb.co.ke/press/publications/ reports/5-kenya-national-dairy-master-plan/file. Accessed 16 June 2016.

Jay, J.M., M.J. Lossner, and A.G. Golden. 2005. Modern Food Microbiology. New York: Springer Science+Business Media Inc.

Kashongwe, B.O., B.O. Bebe, J.W. Matofari, and C.G. Huelsebusch. 2017. Associations between milking practices, somatic cell counts, and milk post-harvest losses in 
smallholder dairy and pastoral camel herds in Kenya. International Journal of Veterinary Science and Medicine 5: 57-64.

KNBS (Kenya National Bureau of Statistics). 2010. Population and housing census: Livestock population by type and districts, 2009. http://www.opendata.go.ke/ datasets/census-vol-ii-q-11-livestock-population-by-type-and-district2009? selectedAttribute=Camels. Accessed 14 Dec 2015.

Mati, B.M., J.M. Muchiri, K. Njenga, F. Penning de Vries, and D.J. Merrey. 2005. Assessing water availability under pastoral livestock systems in drought-prone Isiolo District, Kenya. Working paper 106. Colombo, Sri Lanka: International Water Management Institute (IWMI) http://www.iwmi.cgiar.org/Publications/ Working_Papers/working/WOR106.pdf. Accessed 6 November 2017.

Matofari, J.W., P.L. Shalo, M. Younan, J.N. Nanua, A. Adongo, A. Qabale, and B.N. Misiko. 2013. Analysis of microbial quality and safety of camel (Camelus dromedaries) milk chain and implications in Kenya. Journal of Agricultural Extension and Rural Development 5 (3): 50-54

Messer, J.W., H.M. Behney, and L.O. Leudecke. 1985. Microbiological count methods. In Standard Methods for the Examination of Dairy Products, ed. G.H. Richardson, 133-150. Washington D.C.: American Public Health Association.

Musinga, M., D. Kimenye, and P. Kivolonzi. 2008. The camel milk industry in Kenya. Results of a study commissioned by SNV to explore the potential of camel milk from Isiolo district to access sustainable formal markets. Final report prepared by Resource Mobilization Center (RMC), Nanyuki, Kenya. http://fr.afraca.org/ download/general_rural_finance_publications/Camel-Milk-Value-Chain-TheCase-of-Isiolo-District-A-Study-Report-by-Muli-Musinga-et-al.pdf. Accessed 14 Dec 2014.

Mwangi, A., S.M. Arimi, S. Mbugua, E.K. Kangethe, A.O. Omore, and J.J. McDermott. 2000. Assurance of marketed milk quality in Kenya. Paper presented at Faculty of Veterinary Medicine, Biennial Scientific Conference, 3031, August, 2000. Nairobi: University of Nairobi. https://cgspace.cgiar.org/ handle/10568/1583. Accessed 8 Aug 2014.

Noor, I.M., A.Y. Guliye, M. Tariq, and B.O. Bebe. 2013. Assessment of camel and camel milk marketing practices in an emerging peri-urban production system in Isiolo County, Kenya. Pastoralism: Research, Policy and Practices 3 (28). https://doi.org/ 10.1186/2041-7136-3-28.

Odongo, N.O., P.O. Lamuka, G.O. Abong, J.W. Matofari, and K.A. Abbey. 2016 Physico-chemical and microbiological postharvest losses of camel milk along the camel milk value chain in Isiolo, Kenya. Current Research in Nutrition and Food Science 4 (2): 80-89.

Wayua, F.O., M.W. Okoth, and J. Wangoh. 2012. Survey of post-harvest handling, preservation and processing practices along the camel milk chain in Isiolo District, Kenya. African Journal of Food, Nutrition, and Development 12 (7).

Younan, M, and Abdulrahman. 2004. Milk hygiene and udder health. In Milk from the camel: Handbook on products and processing, ed. Z Farah and A Fischer, 67-76. Zurich/Singen, Switzerland vdf. Hochschulverlag.

\section{Submit your manuscript to a SpringerOpen ${ }^{\circ}$ journal and benefit from:}

- Convenient online submission

- Rigorous peer review

- Open access: articles freely available online

- High visibility within the field

- Retaining the copyright to your article 